\title{
Métodos e eficácia da antissepsia cirúrgica das mãos no pré-operatório
}

\author{
Methods and effectiveness of surgical antisepsy of the hands in the preoperative \\ Métodos y eficacia del antisepsia quirúrgica de las manos en el preoperatorio
}

\author{
Antônio Carlos Pereira Junior \\ ORCID: https://orcid.org/0000-0002-4111-7438 \\ Faculdade de Santa Catarina, Brasil \\ E-mail: acpjunior5@hotmail.com \\ Ana Paula Madalena da Silva \\ ORCID: https://orcid.org/0000-0003-1811-8325 \\ Universidade Federal de Santa Catarina, Brasil \\ E-mail: anapaulamadalenadasilva@gmail.com \\ Juliana Mendes Nascimento \\ ORCID: https://orcid.org/0000-0001-8423-3941 \\ Universidade Federal de Santa Catarina, Brasil \\ E-mail: julianamendesnascimento31@gmail.com \\ Maritza Regina Stuart \\ ORCID: https://orcid.org/0000-0003-4470-5232 \\ Universidade Federal de Santa Catarina, Brasil \\ E-mail: maritzareginas@yahoo.com.br \\ Bianca Pimentel \\ ORCID: https://orcid.org/0000-0002-7927-4631 \\ Centro Universitário FACVEST, Brasil \\ E-mail: pimentelbi90@gmail.com
}

\begin{abstract}
Resumo
Objetivo: Esta pesquisa visa buscar e comparar os métodos utilizados na realização da antissepsia cirúrgica das mãos no pré-operatório e avaliar qual método se mostra mais adequado e mais eficaz para o uso da equipe cirúrgica, visando uma assistência mais segura ao paciente. Metodologia: Trata-se de uma revisão de literatura exploratória de abordagem qualitativa onde foram feitas buscas de materiais publicados entre os anos de 2010 e 2019 na base de dados "Google Acadêmico", onde foram encontrados materiais que subsidiaram o desenvolvimento desta pesquisa. Resultados: Todos os métodos e técnicas utilizados para a realização da antissepsia cirúrgica das mãos apresentam resultados satisfatórios na eliminação da flora residente e transitória, porém, a antissepsia realizada com solução alcoólica foi a que se mostrou mais eficaz. Conclusão: Com os resultados encontrados nesta pesquisa, conclui-se que ela contribui com a qualidade do serviço prestado pela equipe cirúrgica e com o enfermeiro como gestor do centro cirúrgico, servindo de embasamento para a tomada de decisão frente às necessidades e quanto à forma mais adequada de realização da antissepsia cirúrgica das mãos no pré-operatório, proporcionando uma assistência de qualidade e maior segurança para o paciente cirúrgico.
\end{abstract}

Palavras-chave: Cuidados pré-operatórios; Antissepsia; Mãos; Eficácia.

\begin{abstract}
Objective: This research aims to seek and compare the methods used in performing surgical hand antisepsis in the preoperative period and to evaluate which method is more appropriate and effective for the use of the surgical team, aiming at a safer patient care. Methodology: This is an exploratory literature review with a qualitative approach, where searches were made for materials published between 2010 and 2019 in the "Google Academic" database, where materials that supported the development of this research were found. Results: All methods and techniques used to perform surgical hand antisepsis present satisfactory results in the elimination of resident and transient flora, however, antisepsis performed with alcoholic solution was the most effective. Conclusion: With the results found in this research, it is concluded that it contributes to the quality of the service provided by the surgical team and with the nurse as the manager of the operating room, serving as a basis for decision making in light of the needs and the way more adequate preoperative surgical hand antisepsis, providing quality care and greater safety for the surgical patient.

Keywords: Preoperative care; Antisepsis; Hands; Efficiency.
\end{abstract}

\section{Resumen}

Objetivo: Esta investigación tiene como objetivo buscar y comparar los métodos utilizados en la realización de la antisepsia quirúrgica de la mano en el período preoperatorio y evaluar qué método es más apropiado y efectivo para el uso del equipo quirúrgico, con el objetivo de una atención más segura al paciente. Metodología: Se trata de una revisión bibliográfica exploratoria con enfoque cualitativo, donde se realizaron búsquedas de materiales publicados 
entre 2010 y 2019 en la base de datos "Google Academic", donde se encontraron materiales que sustentaron el desarrollo de esta investigación. Resultados: Todos los métodos y técnicas utilizados para realizar la antisepsia quirúrgica de la mano presentan resultados satisfactorios en la eliminación de la flora residente y transitoria, sin embargo, la antisepsia realizada con solución alcohólica fue la más efectiva. Conclusión: Con los resultados encontrados en esta investigación, se concluye que contribuye a la calidad del servicio brindado por el equipo quirúrgico y con la enfermera como gerente del quirófano, sirviendo de base para la toma de decisiones a la luz de las necesidades y la forma de antisepsia quirúrgica preoperatoria más adecuada de la mano, brindando una atención de calidad y una mayor seguridad para el paciente quirúrgico.

Palabras clave: Atención preoperatoria; Antisepsia; Manos; Eficiencia.

\section{Introdução}

A enfermagem atua em diferentes áreas do cuidado ao paciente, uma delas, é durante a instrumentação cirúrgica, onde o profissional deve tomar alguns cuidados cruciais relacionados à segurança do paciente. Segundo Gök, Kabu e Özbayir (2016) um destes cuidados é a correta antissepsia cirúrgica das mãos, realizada antes da paramentação cirúrgica, e visa reduzir a flora transitória nas mãos do profissional além de ser capaz de diminuir o risco de contaminação da ferida operatória e de infecção do sítio cirúrgico para o paciente.

Segundo a Agência Nacional de Vigilância Sanitária, a antissepsia cirúrgica das mãos é um procedimento realizado com auxílio de antisséptico degermante em mãos e antebraços com a finalidade de eliminar a flora transitória e reduzir a residente presente no profissional, proporcionando também, efeito antisséptico residual. Ela deve ser realizada antes da paramentação cirúrgica, que segundo Duarte e Leite (2013), se dá através do uso de máscaras, óculos de proteção, aventais e luvas estéreis e que protege o paciente e o sítio cirúrgico de microrganismos presentes no profissional, além de proteger o profissional de exposição a materiais biológicos provenientes do paciente cirúrgico.

Apesar do uso de luvas estéreis durante a paramentação cirúrgica, Barreto (2012) e Gonçalves, Graziano e Kawagoe (2012) nos trazem que além de apresentarem permeabilidade, cerca de $18 \%$ delas apresentam micro perfurações que passam despercebidas pela equipe e que pode aumentar a chance de infecção do sítio cirúrgico para o paciente, infecções esta que conforme Dos Santos, Burci e Weigert (2018) para serem evitadas, medidas devem ser tomadas desde o pré-operatório e envolvendo todos os profissionais da equipe cirúrgica.

Conforme abordado por Nunes (2016), o profissional enfermeiro participa ativamente do processo cirúrgico do paciente, onde além de atividades como supervisionar e coordenar o centro cirúrgico, ele é responsável por ações como as de controle de infecção hospitalar. Neste sentido, ele toma ações preventivas e corretivas quando algo precisa ser feito ou mudado para uma prática mais segura ao paciente, assim, quando falamos em antissepsia cirúrgica realizada antes do início da cirurgia, o enfermeiro deve conhecer quais produtos e métodos de utilização deles podem ser utilizados para não expor seus pacientes a riscos de contaminação, mostrando a importância que a antissepsia cirúrgica das mãos tem para a prática de um exercício de enfermagem que contribua com mais segurança ao paciente cirúrgico.

Para tal, existem produtos e técnicas que devem ser utilizados para minimizar este risco de contaminação e eventuais infecções, onde cabe ao profissional seguir uma série de recomendações, que quando executadas corretamente e com os produtos adequados, promovem a redução da flora presente em sua pele.

Existe, atualmente, segundo Maciel (2013) e Dotto et al. (2015), mais de um produto e mais de uma forma de se realizar tal procedimento, como o uso de soluções degermantes de clorexidina e polivinilpirrolidona iodado (PVPI) com ou sem uso de escovas descartáveis e soluções alcoólicas, portanto, compará-los é relevante para a enfermagem pois cabe ao enfermeiro conhecer qual apresenta maior eficácia e segurança na contribuição da redução de infecções cirúrgicas e na prestação do cuidado ao paciente cirúrgico, para que ele seja exercido com embasamento científico, qualidade, presteza, confiança e segurança, além de possibilitar que ele seja o disseminador de conhecimento sobre esta prática e possa tomar decisões junto com o restante da equipe cirúrgica quanto à realização deste procedimento. 
Onde houver um centro cirúrgico, irá haver um paciente necessitando dos cuidados de enfermagem específicos a ele. Sabendo qual a melhor forma de se executar a antissepsia cirúrgica das mãos, será possível que o enfermeiro contribua prestando uma assistência de qualidade e com maior segurança em relação à prevenção de infecções cirúrgicas, pois sendo ele conhecedor destes métodos disponíveis e de suas respectivas eficácias, e agente capaz de tomar ações preventivas e corretivas relacionadas à prevenção de infecções, certamente poderá agir com conhecimento e embasamento científico na tomada de decisão quando à melhor utilização dos antissépticos e suas formas de uso em prol ao paciente cirúrgico.

Através da prática cotidiana de trabalho dos enfermeiros pesquisadores dentro de um centro cirúrgico, percebeu-se que durante a realização da antissepsia cirúrgica das mãos, alguns profissionais questionavam o método que era empregado para desenvolver tal atividade, fato que contribuiu para o nascimento da ideia de desenvolver uma pesquisa que pudesse elucidar esta questão e servir de base para consulta e eventual mudança de rotina de trabalho.

Então, levando em consideração as atividades realizadas pelo enfermeiro em seu trabalho dentro de um centro cirúrgico, esta pesquisa visa buscar e comparar os métodos utilizados na realização da antissepsia cirúrgica das mãos no préoperatório e dentre estes, buscar qual se mostra mais eficaz e, portanto, oferece uma maior segurança para o paciente cirúrgico, podendo servir de subsídio para tomada de decisão e conhecimento quanto à forma mais adequada da realização da antissepsia cirúrgica das mãos no pré-operatório.

\section{Metodologia}

A revisão de literatura, operacionalizada obedecendo-se seis etapas. Primeira etapa: identificação do tema e seleção da hipótese ou questão de pesquisa. Segunda etapa: estabelecimento de critérios para inclusão e exclusão de estudos/ amostragem ou busca na literatura. Terceira etapa: definição das informações a serem extraídas dos estudos selecionados. Quarta etapa: avaliação dos estudos incluídos na revisão. Quinta etapa: interpretação dos resultados. Sexta etapa: apresentação da revisão/síntese do conhecimento (MENDES et al., 2008).

Por haver a necessidade de esclarecimento sobre um problema levantado e subsidiar dados que auxiliem em sua elucidação, trata-se de uma pesquisa exploratória, que conforme Gil (1991) envolve levantamento bibliográfico através de material já publicado em artigos científicos, onde são levantados elementos que irão servir de referencial teórico na busca das informações relevantes ao objetivo da pesquisa e proporcionar maior familiaridade com o problema a fim de construir uma hipótese ou torná-lo explícito.

A natureza dos dados é tratada por Silva e Menezes (2005) como um estudo qualitativo, onde este é descritivo, sem possuir estrutura específica e não requer métodos e técnicas estatísticas, permitindo uma melhor compreensão pelo autor de seus objetivos.

As buscas foram feitas na base de dados "Google Acadêmico" por meio da internet, por se tratar de uma base de dados que contempla os resultados presentes em outras bases de dados. Foram feitas buscas por pesquisas publicadas em português e inglês, onde como estratégia de busca foram utilizadas as combinações de palavras "antissepsia", "cirúrgica" e "mãos", tendo sido refinado por período de 2010 a 2019 e refinado novamente sendo acrescentada a combinação das palavras "métodos", "eficácia", "pré-operatório" e "comparação".

A partir dos filtros por palavras e tempo utilizados, foram listados 203 resultados, onde destes, após ser feita uma análise dos títulos quanto à pertinência ao estudo, se fosse condizente ao tema de pesquisa, seu resumo era lido para incluir ou excluir da base de dados desta pesquisa.

Assim, quando incluídos, conforme o material foi sendo lido e selecionado, as informações pertinentes a esta pesquisa foram sendo levantadas até totalizar 17 artigos, que estão listados no Quadro 1 e que tratavam sobre métodos, suas formas de utilização e/ou eficácia de antissépticos utilizados na antissepsia cirúrgica das mãos. Após análise destes materiais, os 
pesquisadores concluíram que os demais encontrados, embora pudessem ser condizentes com o tema, tornavam-se redundantes e assim não foram considerados para corroborar ao resultado desta pesquisa.

Por fim, os dados levantados foram analisados para compor os resultados e discussões apresentados nesta pesquisa.

\section{Resultados e Discussão}

Quadro 1. Resultado pela busca de materiais na base de dados utilizada.

\begin{tabular}{|c|c|c|c|c|}
\hline $\begin{array}{l}\text { Autor e ano } \\
\text { de } \\
\text { Publicação }\end{array}$ & Título & Objetivos & $\begin{array}{l}\text { Tipo de } \\
\text { Estudo }\end{array}$ & Evidência \\
\hline $\begin{array}{l}\text { Maciel, M. } \\
\text { A. (2013) }\end{array}$ & $\begin{array}{l}\text { Lavagem ré- } \\
\text { cirúrgica das mãos: } \\
\text { uma revisão de } \\
\text { literatura. }\end{array}$ & $\begin{array}{l}\text { Verificar qual a melhor } \\
\text { forma de higienizar as mãos } \\
\text { a fim de esclarecer quais as } \\
\text { condutas mais indicadas } \\
\text { para a lavagem das mãos } \\
\text { pré-cirúrgica nos hospitais } \\
\text { brasileiros. }\end{array}$ & $\begin{array}{l}\text { Revisão de } \\
\text { Literatura. }\end{array}$ & $\begin{array}{l}\text { Os estudos evidenciam a clorexidina e os } \\
\text { iodóforos como as substâncias mais } \\
\text { utilizadas para antissepsia cirúrgica das } \\
\text { mãos no Brasil. Entre o álcool, a } \\
\text { clorexidina e os iodóforos, as soluções } \\
\text { alcoólicas são as mais indicadas e que o } \\
\text { uso de escovas não aumenta a eficácia da } \\
\text { lavagem das mãos. }\end{array}$ \\
\hline $\begin{array}{c}\text { Barreto et al. } \\
\text { (2009) }\end{array}$ & $\begin{array}{l}\text { A antissepsia } \\
\text { cirúrgica das mãos no } \\
\text { cotidiano de um } \\
\text { Centro Cirúrgico. }\end{array}$ & $\begin{array}{l}\text { Observar e analisar a prática } \\
\text { da antissepsia cirúrgica das } \\
\text { mãos em um centro } \\
\text { cirúrgico de um hospital de } \\
\text { ensino. }\end{array}$ & $\begin{array}{l}\text { Estudo } \\
\text { descritivo } \\
\text { quantitativo. }\end{array}$ & $\begin{array}{l}\text { Em } 87 \% \text { houve escovação errônea de } \\
\text { antebraços e dorso das mãos, em } 94,5 \% \\
\text { não foram mantidos movimentos } \\
\text { unidirecionais, e } 31,5 \% \text { contaminaram as } \\
\text { mãos após a antissepsia. }\end{array}$ \\
\hline $\begin{array}{c}\text { Primo et al. } \\
\text { (2010) }\end{array}$ & $\begin{array}{l}\text { Adesão à prática de } \\
\text { higienização das mãos } \\
\text { por profissionais de } \\
\text { saúde de um Hospital } \\
\text { Universitário. }\end{array}$ & $\begin{array}{l}\text { Avaliar a adesão dos } \\
\text { profissionais da área de } \\
\text { saúde quanto à prática de } \\
\text { higienização das mãos. }\end{array}$ & $\begin{array}{l}\text { Pesquisa } \\
\text { descritiva } \\
\text { quantitativa. }\end{array}$ & $\begin{array}{l}\text { A adesão à HM, não se apresenta } \\
\text { incorporada à prática diária dos } \\
\text { profissionais de saúde dessa instituição e, } \\
\text { desta forma, ações educativas com vistas a } \\
\text { orientar e motivar esses profissionais à } \\
\text { prática correta e frequente de HM devem } \\
\text { ser discutidas e implementadas. }\end{array}$ \\
\hline $\begin{array}{c}\text { Menezes et } \\
\text { al. } \\
\text { (2016) }\end{array}$ & $\begin{array}{l}\text { Avaliação } \\
\text { microbiológica da } \\
\text { antissepsia pré- } \\
\text { operatória das mãos } \\
\text { de profissionais de } \\
\text { enfermagem de um } \\
\text { centro cirúrgico. }\end{array}$ & $\begin{array}{l}\text { Avaliar a microbiota } \\
\text { presente nas mãos dos } \\
\text { profissionais antes e após } \\
\text { antissepsia pré-operatória, } \\
\text { com escovação com } \\
\text { clorexidina e técnica de } \\
\text { fricção com solução } \\
\text { alcoólica. }\end{array}$ & $\begin{array}{l}\text { Estudo } \\
\text { transversal. }\end{array}$ & $\begin{array}{l}\text { A solução antisséptica alcoólica foi mais } \\
\text { eficaz se comparada à técnica tradicional } \\
\text { de escovação com digluconato de } \\
\text { clorexidina } 2 \% \text {. }\end{array}$ \\
\hline $\begin{array}{c}\text { Goulart et al. } \\
\text { (2011) }\end{array}$ & $\begin{array}{l}\text { Avaliação } \\
\text { microbiológica da } \\
\text { antissepsia pré- } \\
\text { operatória das mãos. }\end{array}$ & $\begin{array}{l}\text { Comparar a carga } \\
\text { microbiana após a } \\
\text { antissepsia das mãos, } \\
\text { utilizando dois protocolos, } \\
\text { um conforme a técnica da } \\
\text { OMS e outro modificado. }\end{array}$ & $\begin{array}{l}\text { Estudo } \\
\text { transversal. }\end{array}$ & $\begin{array}{l}\text { As técnicas apresentaram resultados } \\
\text { similares após a antissepsia e a cirurgia. A } \\
\text { técnica modificada exige um menor tempo } \\
\text { de antissepsia com menor rigidez, o que } \\
\text { pode aumentar sua adesão. }\end{array}$ \\
\hline $\begin{array}{c}\text { Cunha et al. } \\
\text { (2011) }\end{array}$ & $\begin{array}{l}\text { Eficácia de três } \\
\text { métodos }\end{array}$ & $\begin{array}{lr}\text { Avaliar três } & \text { métodos para } \\
\text { degermação } & \text { cirúrgica } \\
\text { utilizando } & \text { clorexidina } \\
\text { degermante } & 2 \% \text { : com } \\
\text { escova, com } & \text { esponja e sem } \\
\text { artefato. }\end{array}$ & $\begin{array}{l}\text { Estudo } \\
\text { transversal. }\end{array}$ & $\begin{array}{l}\text { Não houve diferença significante na } \\
\text { redução microbiana entre os três métodos } \\
\text { analisados ( } \mathrm{p}=0,148 \text { ), o que teoricamente } \\
\text { descarta a necessidade da continuidade do } \\
\text { uso de escovas e esponjas para a } \\
\text { realização da degermação das mãos. }\end{array}$ \\
\hline
\end{tabular}




\begin{tabular}{|c|c|c|c|c|}
\hline $\begin{array}{c}\text { Dotto et al. } \\
\text { (2015) }\end{array}$ & $\begin{array}{l}\text { Eficácia de dois } \\
\text { métodos } \\
\text { degermação das mãos. }\end{array}$ & $\begin{array}{l}\text { Avaliar a eficácia da } \\
\text { lavagem cirúrgica das mãos } \\
\text { e antebraços com escova } \\
\text { com clorexidina a } 2 \% \text {, } \\
\text { comparando com o método } \\
\text { de fricção das mãos e } \\
\text { antebraço com sabonete } \\
\text { líquido de clorexidina a } 2 \% \text {. }\end{array}$ & $\begin{array}{l}\text { Ensaio } \\
\text { Clínico } \\
\text { randomizad } \\
\text { o. }\end{array}$ & $\begin{array}{l}\text { A higienização das mãos pelo método de } \\
\text { fricção com sabonete contendo clorexidina } \\
\text { a } 2 \% \text { foi mais eficaz quando comparada à } \\
\text { realizada com escova impregnada com } \\
\text { clorexidina a } 2 \% \text {, sugerindo um método de } \\
\text { preparo pré-cirúrgico das mãos mais } \\
\text { rápido, eficaz e menos oneroso. }\end{array}$ \\
\hline $\begin{array}{c}\text { Gonçalves et } \\
\text { al. (2011) }\end{array}$ & 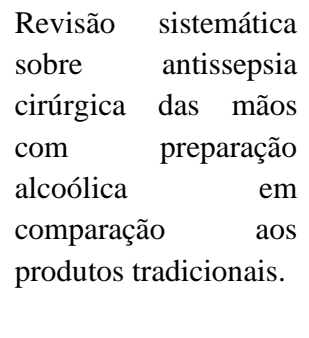 & $\begin{array}{l}\text { Comparar a eficácia de } \\
\text { preparações alcoólicas com } \\
\text { os produtos tradicionais na } \\
\text { antissepsia cirúrgica das } \\
\text { mãos. }\end{array}$ & $\begin{array}{l}\text { Revisão } \\
\text { sistemática. }\end{array}$ & $\begin{array}{l}\text { As preparações alcoólicas tiveram uma } \\
\text { redução microbiana igual e/ou maior aos } \\
\text { produtos tradicionais em } 17 \text { estudos e } \\
\text { inferior em 4; as taxas de infecções do } \\
\text { sítio cirúrgico foram similares. Portanto, } \\
\text { existe evidência científica segura das } \\
\text { preparações alcoólicas para antissepsia } \\
\text { cirúrgica das mãos. }\end{array}$ \\
\hline $\begin{array}{l}\text { Shen et al. } \\
\text { (2013) }\end{array}$ & $\begin{array}{l}\text { Comparação da } \\
\text { eficácia } \\
\text { antimicrobiana entre } \\
\text { fricção das mãos com } \\
\text { solução à base de } \\
\text { álcool e escovação } \\
\text { cirúrgica em um } \\
\text { centro médico. }\end{array}$ & 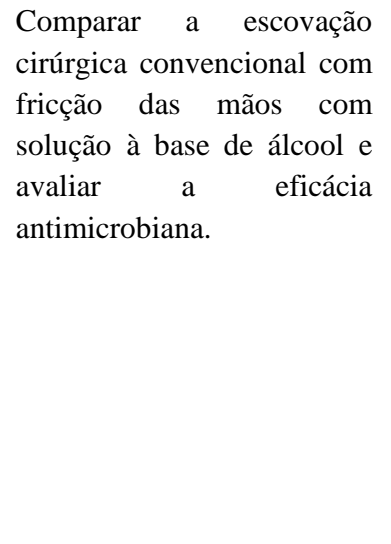 & $\begin{array}{l}\text { Estudo } \\
\text { transversal. }\end{array}$ & $\begin{array}{l}\text { A taxa de cultura positiva da fricção das } \\
\text { mãos com álcool foi de } 6,2 \% \text { antes das } \\
\text { operações e } 10,8 \% \text { após. Ambas menores } \\
\text { do que a escovação cirúrgica convencional } \\
\text { [47,6\% antes das operações (p <0,001) e } \\
25,4 \% \text { após as operações (p Z } 0,03)] \text {. A } \\
\text { análise mostrou que a condição da mão } \\
\text { prévia (p Z } 0,21) \text { e tipo de cirurgia (p } \\
<0,12 \text { ) foram menos relevantes, mas } \\
\text { friccionar as mãos com solução à base de } \\
\text { álcool foi um fator de proteção } \\
\text { significativo para culturas de mãos } \\
\text { positivas. }\end{array}$ \\
\hline $\begin{array}{l}\text { Gok et al. } \\
\text { (2016) }\end{array}$ & $\begin{array}{l}\text { Lavagem cirúrgica } \\
\text { das mãos: uma } \\
\text { revisão sistemática. }\end{array}$ & 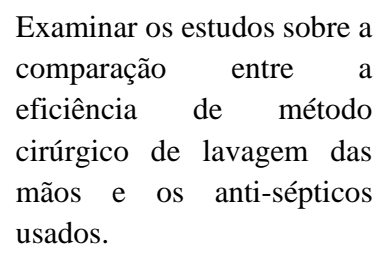 & $\begin{array}{l}\text { Revisão } \\
\text { integrativa. }\end{array}$ & $\begin{array}{l}\text { A realização de anti-sepsia cirúrgica das } \\
\text { mãos é um dos princípios mais } \\
\text { importantes na prevenção das infecções do } \\
\text { sítio cirúrgico. A eficiência e preferência } \\
\text { das soluções cirúrgicas para a lavagem das } \\
\text { mãos ainda é uma questão controversa. }\end{array}$ \\
\hline $\begin{array}{c}\text { Darouiche } e t \\
\text { al. } \\
\text { (2010) }\end{array}$ & $\begin{array}{l}\text { Clorexidina-Alcool } \\
\text { versus Povidona-Iodo } \\
\text { para antissepsia de } \\
\text { sítio cirúrgico }\end{array}$ & $\begin{array}{l}\text { Comprovar a hipótese de } \\
\text { que a antissepsia pré- } \\
\text { operatória com clorexidina- } \\
\text { álcool é mais protetora } \\
\text { contra infecções do que a } \\
\text { povidona-iodo. }\end{array}$ & $\begin{array}{l}\text { Ensaio } \\
\text { clínico. }\end{array}$ & $\begin{array}{l}\text { A antissepsia pré-operatória da pele do } \\
\text { paciente com clorexidina-álcool é superior } \\
\text { à povidona-iodo para prevenir a infecção } \\
\text { do sítio cirúrgico. }\end{array}$ \\
\hline $\begin{array}{l}\text { Rehman et } \\
\quad \text { al. } \\
\text { (2010) }\end{array}$ & $\begin{array}{l}\text { Antissepsia cirúrgica } \\
\text { das mãos: o que os } \\
\text { cirurgiões precisam } \\
\text { saber? }\end{array}$ & 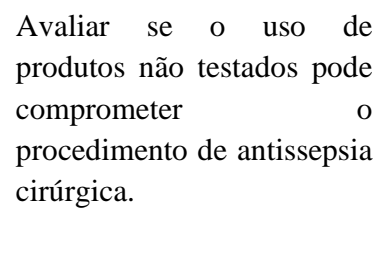 & $\begin{array}{l}\text { Revisão } \\
\text { integrativa }\end{array}$ & $\begin{array}{l}\text { O padrão ouro para a antissepsia cirúrgica } \\
\text { das mãos é a aplicação de solução à base } \\
\text { de álcool e sua aplicação por } 90 \text { segundos } \\
\text { é suficiente. Escovas não são } \\
\text { recomendadas para preparação cirúrgica } \\
\text { das mãos. }\end{array}$ \\
\hline $\begin{array}{l}\text { Jarral et al. } \\
\text { (2011) }\end{array}$ & $\begin{array}{l}\text { Os cirurgiões devem } \\
\text { se escovar com } \\
\text { clorexidina ou iodo } \\
\text { antes da cirurgia? }\end{array}$ & $\begin{array}{l}\text { Verificar se a clorexidina é } \\
\text { equivalente ou superior ao } \\
\text { PVPI durante a escovação } \\
\text { cirúrgica das mãos. }\end{array}$ & $\begin{array}{l}\text { Revisão } \\
\text { sistemática. }\end{array}$ & $\begin{array}{l}\text { Embora a clorexidina e a iodopovidona } \\
\text { reduzam a contagem bacteriana após a } \\
\text { lavagem, o efeito da clorexidina é mais } \\
\text { profundo e mais duradouro. }\end{array}$ \\
\hline
\end{tabular}




\begin{tabular}{|c|c|c|c|c|}
\hline $\begin{array}{l}\text { Hennig et al. } \\
\text { (2017) }\end{array}$ & $\begin{array}{l}\text { A clorexidina não é } \\
\text { um elemento } \\
\text { essencial rem } \\
\text { preparação a base de } \\
\text { álcool na antissepsia } \\
\text { cirúrgica das mãos: } \\
\text { um estudo } \\
\text { comparativo de duas } \\
\text { escovações das mãos } \\
\text { com base em um } \\
\text { protocolo teste } \\
\text { modificado. }\end{array}$ & $\begin{array}{l}\text { Comparar duas formas de } \\
\text { escovação cirúrgica das } \\
\text { mãos com base em um } \\
\text { protocolo teste modificado. }\end{array}$ & $\begin{array}{l}\text { Ensaio } \\
\text { clínico }\end{array}$ & $\begin{array}{l}\text { Uma formulação de álcool testada de } \\
\text { acordo com um protocolo modificado } \\
\text { superou uma formulação de clorexidina } \\
\text { alcoólica imediatamente após a aplicação e } \\
6 \text { h sob luvas cirúrgicas. Assim, as } \\
\text { formulações alcoólicas não requerem } \\
\text { clorexidina para atingir eficácia imediata } \\
\text { potente e sustentada. A clorexidina não é } \\
\text { um elemento essencial para preparação } \\
\text { cirúrgica das mãos à base de álcool. }\end{array}$ \\
\hline $\begin{array}{c}\text { Santos et al. } \\
\text { (2018) }\end{array}$ & $\begin{array}{l}\text { Fatores de risco e } \\
\text { prevenção de infecção } \\
\text { do sítio cirúrgico. }\end{array}$ & $\begin{array}{l}\text { Contribuir } r \text { com } \\
\text { conhecimentos científicos, } \\
\text { referente aos fatores de } \\
\text { risco e métodos de } \\
\text { prevenções relacionados à } \\
\text { infecção do sítio cirúrgico. }\end{array}$ & $\begin{array}{l}\text { Revisão } \\
\text { bibliográfic } \\
\text { a. }\end{array}$ & $\begin{array}{l}\text { Os fatores de risco predisponentes a ISC } \\
\text { estão associados a múltiplos fatores } \\
\text { destacando a desorganização relacionada } \\
\text { ao número de pessoas na sala de cirurgia, a } \\
\text { movimentação das portas, o sistema de } \\
\text { ventilação, a paramentação do médico, o } \\
\text { preparo da pele do paciente, e da } \\
\text { antissepsia das mãos da equipe cirúrgica. } \\
\text { Conclui-se que a prevenção de infecção do } \\
\text { sitio cirúrgico está relacionada aos } \\
\text { cuidados prestados em todo o período } \\
\text { cirúrgico. }\end{array}$ \\
\hline $\begin{array}{l}\text { Prates et al. } \\
\text { (2016) }\end{array}$ & $\begin{array}{l}\text { Implantação de } \\
\text { antissepsia cirúrgica } \\
\text { alcoólica das mãos: } \\
\text { relato de experiência. }\end{array}$ & $\begin{array}{l}\text { Relatar a experiência de } \\
\text { implantação do antisséptico } \\
\text { alcoólico para o preparo das } \\
\text { mãos da equipe cirúrgica. }\end{array}$ & $\begin{array}{l}\text { Relato de } \\
\text { experiência. }\end{array}$ & $\begin{array}{l}\text { Houve considerável adesão à solução } \\
\text { alcoólica e observou-se impacto } \\
\text { econômico e demanda de capacitações } \\
\text { para a técnica correta. }\end{array}$ \\
\hline $\begin{array}{l}\text { Duarte; Leite } \\
\text { (2013) }\end{array}$ & $\begin{array}{l}\text { Paramentação } \\
\text { cirúrgica: artigo de } \\
\text { revisão. }\end{array}$ & $\begin{array}{l}\text { Descrever a paramentação } \\
\text { cirúrgica e suas reais } \\
\text { necessidades. }\end{array}$ & $\begin{array}{l}\text { Revisão de } \\
\text { Literatura }\end{array}$ & $\begin{array}{l}\text { Constitui-se em medida eficaz na redução } \\
\text { dos processos infecciosos pós-operatórios, } \\
\text { mesmo com resultados contraditórios em } \\
\text { vários estudos sobre o reconhecimento das } \\
\text { reais fontes e formas de transmissão dos } \\
\text { microrganismos em um centro cirúrgico. }\end{array}$ \\
\hline
\end{tabular}

Fonte: Google acadêmico.

O Quadro 1 contempla os principais achados nas buscas que compuseram o resultado desta pesquisa e que serão detalhados nas discussões trazem que os principais antissépticos utilizados para a antissepsia cirúrgica das mãos são a solução degermante de polivinilpirrolidona iodado (PVPI) e solução degermante de clorexidina, abordando sua utilização com ou sem o uso de escova estéril, seus tempos de ação, bem como seus efeitos residuais nas mãos dos profissionais. As pesquisas abordam também o uso de soluções antissépticas alcoólicas, onde compara sua utilização com as anteriores levantando questões como custos, tempo destinado para seu uso e ainda problemas resultantes da utilização de certa técnica em detrimento de outra.

Sabidamente, as mãos são capazes de abrigar e transferir microrganismos, seja de um objeto para outro, um paciente para outro e até mesmo do próprio profissional de saúde para o paciente. Assim, através da higienização das mãos, reduzir ou eliminar a microbiota presente, se torna uma medida de fundamental importância na redução de infecções. Maciel (2013) acrescenta ainda que quando se trata de procedimentos cirúrgicos, estes cuidados são ainda mais imprescindíveis. 
Falando especificamente sobre antissepsia cirúrgica das mãos, que é realizada antes da paramentação cirúrgica e antes do procedimento por toda equipe cirúrgica, são utilizados produtos específicos para este fim, como soluções antissépticas e escovas estéreis de uso único. Quando falamos em antissépticos, poder escolher dentre as opções disponíveis qual apresenta melhor resultado, proporciona maiores chances de que o paciente cirúrgico não seja contaminado durante a sua cirurgia. Portanto, a escolha apropriada desempenha um papel fundamental para a equipe cirúrgica, uma vez que desta forma não estará expondo o paciente a riscos.

Maciel (2013) e Dotto et al. (2015), apontam como principais antissépticos utilizados na antissepsia cirúrgica das mãos a solução alcoólica, a solução degermante de polivinilpirrolidona iodado (PVPI) e solução degermante de clorexidina, aplicados ou não com auxílio de escova e esponja.

Gonçalves, Graziano e Kawagoe (2012) ressaltam em sua pesquisa que toda flora transitória deve ser eliminada e a residente reduzida significativamente pelo antisséptico no início da cirurgia e manter inibido o seu crescimento até o final com as mãos enluvadas, pois embora se utilize luvas estéreis, estas podem apresentar micro furos e oferecer risco de contaminação ao paciente através deles. Os autores ressaltam ainda que dentre as principais opções, a solução alcoólica ainda apresenta como vantagem economia de água devido a não necessitar de enxague após sua aplicação, corroborando com Prates et al. (2016) que também observaram vantagens como economia de recursos e custos com a implementação do uso de solução alcoólica na antissepsia cirúrgica das mãos.

Saber que existe mais de uma opção de antisséptico para realizar a antissepsia cirúrgica das mãos não é o suficiente, é necessário conhecer estes produtos e suas formas de utilização, para então, escolher a que será utilizada no cotidiano das atividades profissionais com maior segurança.

Maciel (2013) nos traz que o antisséptico à base de iodo utilizado para a antissepsia cirúrgica das mãos é o PVPI degermante utilizado em conjunto com escova/esponja de uso único e descartável, que embora muito utilizado por possuir ampla ação contra vários tipos de microrganismos, exceto aos vírus e esporos e proporcionar ação redutora na flora bacteriana, está entrando em desuso, pois seu uso continuado em procedimentos cirúrgicos apresenta muitos casos de irritação na pele, podendo desenvolver, quando repetido várias vezes ao longo do dia, o surgimento de dermatite.

Com o uso do PVPI sendo questionado e descontinuado na prática assistencial, outro antisséptico muito utilizado na realização da antissepsia cirúrgica das mãos é a clorexidina, que também possui ampla ação antimicrobiana.

A clorexidina está bastante presente no cotidiano profissional da enfermagem na antissepsia cirúrgica das mãos, apresentando-se em forma de antisséptico degermante onde conforme as pesquisas de Goulart, Assis e Souza (2011), Cunha et al. (2011) e Dotto et al. (2015), pode ser utilizada tanto para escovação quanto em fricção das mãos sem uso de artefatos.

Barreto et al. (2012) nos mostra que ambos são indicados para antissepsia cirúrgica das mãos por se tratar de um procedimento que requer ação prolongada do antisséptico utilizado, porém, o uso da clorexidina se sobrepõe ao do PVPI por apresentar um efeito residual de aproximadamente seis horas enquanto o PVPI em torno de trinta e sessenta minutos.

Além do PVPI e da clorexidina, encontra-se disponível para a antissepsia cirúrgica das mãos, a solução alcoólica, onde sua maioria contém isopropanol, etanol ou n-propanol (Maciel, 2013).

Segundo Menezes et al. (2017), ela vem sendo adotada como alternativa devido a vários fatores, como atividade antimicrobiana, rápida aplicação e ação, economia de materiais, dentre outros e segundo Rehman et al. (2010) por ser o padrão ouro para a antissepsia cirúrgica das mãos a utilização de antissépticos à base de álcool, pois quando comparado seu uso com PVPI e clorexidina, se mostra superior e o mais eficaz método de ação antimicrobiana para realização da antissepsia cirúrgica das mãos.

A clorexidina sob apresentação de antisséptico degermante é citada pela maioria dos estudos encontrados na busca realizada. Muitos estudos, como os de Goulart, Assis e Souza (2011), Cunha et al. (2011) e Dotto et al. (2015), abordam o seu 
uso de duas formas possíveis, tanto utilizando em conjunto com escova/esponja de uso único e descartável para escovação de mãos e antebraço, cuja técnica é exemplificada na Figura 1, como somente realizando lavagem das mãos com fricção do produto na pele.

Figura 1. Técnica de escovação cirúrgica das mãos.

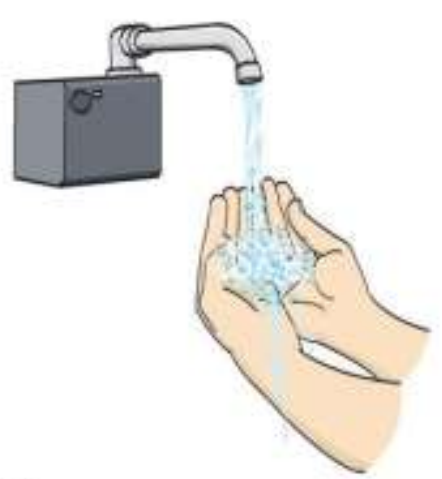

Abrir a torneira, molhar as mâos, antebraços e cotovelos.
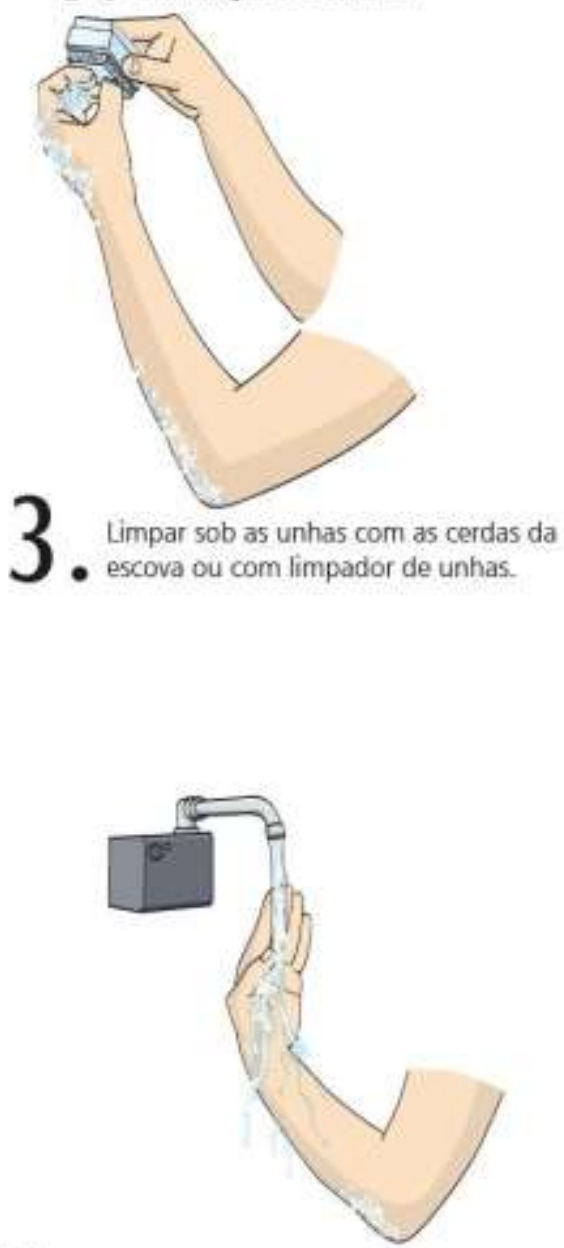

5.

Enxaguar as mâos em água corrente, no sentido das màos para cotovelos, retirando todo residuo do produto. Fechar a tomeira com o cotovelo, joelho ou pés, se a torneira náo possuir fotosensot.

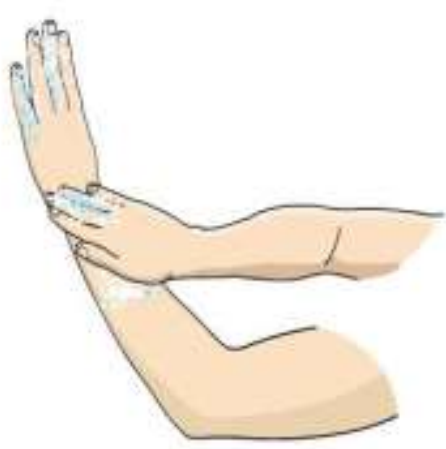

2 Recolher, com as mâos em concha, o anticotovelo. No caso de escova impregnada com anti-séptico, pressione a parte da esponja contra a pele e espalhe por todas as partes.
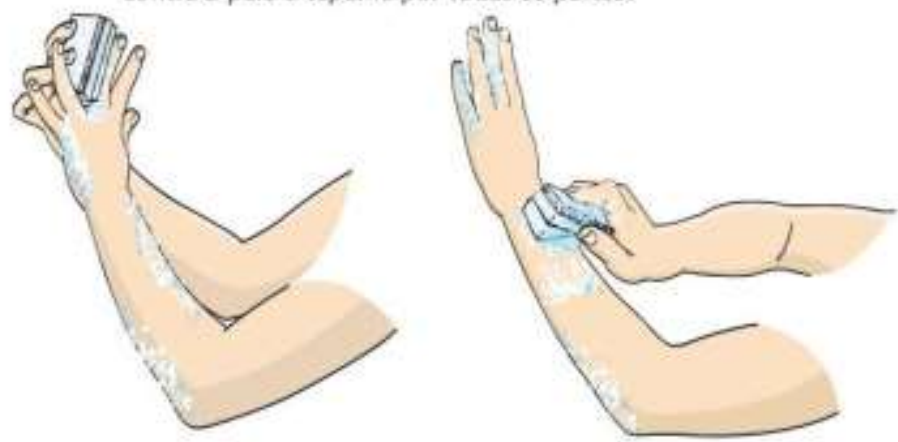

Friccionar as mãos, observando dedos, espaços interdigitais e antebraços por - no mínimo 3 a 5 minutos, mantendo as mãos acima dos cotovelos.
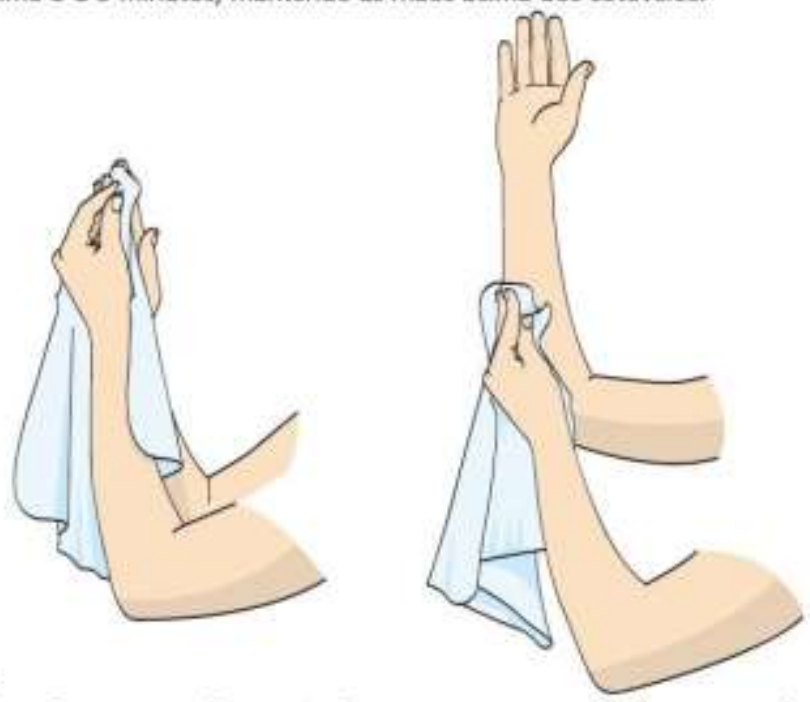

Enxugar as mãos em toalhas ou compressas estéreis, com movimentos compressivos, iniciando pelas măos e seguindo pelo antebraço e cotovelo, atentando para utilizar as diferentes dobras da toalha/ compressa para regiōes distintas.

Fonte: Brasil (2014). 
A Figura 1 exemplifica a técnica de utilização de antisséptico degermante com o uso de escova estéril de uso único e descartável. Seguir a técnica recomendada é importante para a correta eficácia do produto e conhece-la se faz necessário para toda a equipe cirúrgica para garantir que o paciente cirúrgico não seja submetido a risco de infecções por má utilização da técnica.

Goulart, Assis e Souza (2011) comparam o uso da clorexidina destas duas formas e trazem como contribuição que ambas as formas são aceitáveis para a realização do procedimento de forma satisfatória, pois ambas se mostraram ser similar imediatamente após sua utilização e sem demonstrar diferença significativa após a cirurgia.

Além de mostrarem o uso da clorexidina destas duas formas possíveis, Cunha et al. (2011), citam o desuso de artefatos na degermação das mãos, pois o principal fator na redução microbiana é o princípio ativo, independe de uso de escova, e de que a friç̧ão das mãos é melhor tolerado na pele quando dispensado o uso destes artefatos.

Barreto et al. (2012), Menezes et al. (2017), Cunha et al. (2011) e Shen et al. (2015), abordam ainda que o uso de artefatos na degermação com clorexidina propicia o aparecimento de lesões na pele do profissional, que ao invés de ser benéfico acaba expondo a risco de contaminação tanto o profissional como o paciente, além de levantarem um melhor custo benefício quando estes não são utilizados.

Outro problema levantado referente ao uso de clorexidina com artefato por Barreto et al. (2012) é a falta de padronização do procedimento, onde traz como contribuição que as instituições que continuam utilizando este método de antissepsia cirúrgica das mãos, devem criar padronização e acompanhamento da técnica para garantir uma assistência segura ao paciente cirúrgico.

Menezes et al. (2017) e Lopes (2019) nos trazem que o uso das soluções alcoólicas na antissepsia cirúrgica das mãos no Brasil ainda é pouco difundida mesmo perante suas vantagens. Menezes et al. (2017) citam ainda em seu estudo, que na Europa seu uso já é adotado há vários anos devido a fatores como custo e facilidade. Os autores trazem que para a utilização de solução alcoólica na antissepsia cirúrgica das mãos não é necessária à lavagem das mãos previamente, desde que elas estejam limpas, sem sujidades aparentes ou em grande quantidade, o que cita como sendo um ponto de estímulo ao seu uso pelos profissionais de saúde que trabalham em cirurgias, principalmente pelo tempo que se dedica a esta atividade por várias vezes durante o dia e pelo tempo da escovação ser superior ao da fricção com solução alcoólica.

Tão importante quanto conhecer os antissépticos e saber o melhor método a ser utilizado com eles, é conhecer resultados de comparações entre eles que leve o profissional a uma escolha consciente e segura quanto a melhor forma de se realizar a antissepsia cirúrgica das mãos.

Alguns autores abordam comparações com a utilização de degermante á base de PVPI e clorexidina, onde em um deles, Goulart, Assis e Souza (2011) nos traz que não existem muitas evidências científicas em respeito ao uso do PVPI, porém, recomendam que devam ser utilizadas as soluções degermante à base de clorexidina ao invés deste.

Maciel (2013) contribui com sua pesquisa quando nos diz que comparada à ação do PVPI com a clorexidina, tanto após a realização do seu uso quanto em comparação tardia após três horas utilizando luvas estéreis, que a clorexidina obteve melhores índices do que o PVPI, e que este não obteve resultado significativo na redução de microrganismos presente nas mãos dos profissionais, mostrando, portanto, uma eficácia superior da clorexidina quando comparada ao PVPI.

Jarral et al. (2011) através de uma revisão comparando a utilização de degermantes à base de clorexidina e PVPI afirma em seus resultados que ambas apresentam ação antimicrobiana imediata, porém, a clorexidina apresenta maior potencial, além de o PVPI não apresentar ação residual quando comparado com a clorexidina.

Ainda falando em comparação entre PVPI e clorexidina, embora não falando propriamente de soluções degermantes, mas sim de soluções alcoólicas à base de clorexidina e PVPI utilizadas para antissepsia na pele do paciente no sítio cirúrgico, 
Darouiche et al. (2010) também demonstram em seus resultados uma maior eficácia da clorexidina quando comparada ao PVPI.

Embora estes autores não tratem especificamente de antissepsia cirúrgica das mãos, mas sim de antissepsia de sítio cirúrgico, por fazer comparação entre as duas substâncias, acredita-se na importância de ser citado para continuar dando embasamento aos resultados deste trabalho.

Além das comparações já citadas, outras pesquisas comparam a utilização da clorexidina com ela mesma, porém, utilizando-se de métodos diferentes. Goulart, Assis e Souza (2011) fizeram uma comparação entre o uso da técnica de escovação das mãos com clorexidina e friç̧ão das mãos com clorexidina, ambas degermante, onde apresenta como resultado, que ambas são similares imediatamente ao uso e após a cirurgia na ação antimicrobiana.

Indo ao encontro dos autores anterior, Cunha et al. (2011) também traz como contribuição após seus resultados, a exclusão da escova para degermação com clorexidina, pois sua pesquisa utilizou de três métodos diferentes com o emprego da clorexidina degermante, um deles utilizando somente a escova com o antisséptico, outro método utilizando somente a esponja com o antisséptico e, por fim, somente a fricção com o antisséptico e ambos os métodos se mostraram equiparados em eficácia.

Ainda comparando os métodos de utilização de clorexidina degermante, Dotto et al. (2015) também compararam a escovação com a fricção do antisséptico nas mãos e antebraços. Eles também concluíram e sugerem que a fricção das mãos com clorexidina sem escova é um método eficaz e menos oneroso na ação antimicrobiana de flora residente e transitória na pele.

Tanto Goulart, Assis e Souza (2011), Cunha et al. (2011), Dotto et al. (2015) e Rehman (2010) trazem a informação que o uso da escova em conjunto com a clorexidina degermante não traz benefícios relacionas à descontaminação adicional, além de causar desconforto e oferecer risco de lesão na pele do profissional que aumenta o risco de infecção a ele e ao paciente. Sugerem que o uso da clorexidina degermante seja feito apenas pelo método de fricção das mãos e antebraços e que o uso das escovas, além de não se mostrar superior ao método de friç̧ão, gera custos adicionais às instituições.

Além do risco de lesão já mencionado, Dotto et al. (2015) e Barreto et al. (2012) trazem ainda que além deste, o desconforto causado pela fricção da escova com a pele do profissional, pode levá-lo a reduzir o tempo da escovação, colocando a técnica em risco e ao contrário de ser benéfico, pode por em risco o binômio profissional-paciente.

Estes estudos são importantes para servir de embasamento de escolha de qual método se mostra mais eficaz quanto ao emprego da clorexidina degermante na realização da antissepsia cirúrgica das mãos no pré-operatório pelos profissionais de enfermagem, uma vez que os resultados já apresentados mostram redução do risco de lesão no profissional causado pelo atrito da escova com a pele e, consequentemente, o risco de exposição do paciente a fatores que podem propiciar o surgimento de infecções, além de diminuir os gastos com a compra de escova e manter a qualidade e segurança do serviço prestado.

Algumas pesquisas, como as de Shen et al. (2015), Gonçalves, Graziano e Kawagoe (2012), Menezes et al. (2017), Henning (2017) e Menezes et al. (2017) foram encontradas utilizando as soluções alcoólicas para fricção de mãos e antebraços na antissepsia cirúrgica das mãos, exemplificada na Figura 2. 
Figura 2. Técnica de antissepsia cirúrgica das mãos com solução alcoólica.

\section{Técnica para Antissepsia Cirúrgica das Mãos com Produto à Base de Álcool}

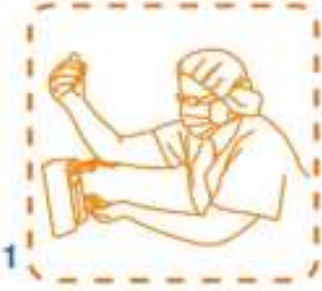

Coloque aptoximadamente $5 \mathrm{ml}$ ( 3 doses) de PBA na palma da sua māo esquerda, usando 0 cotovelo do outro braço para operar o dispensador.

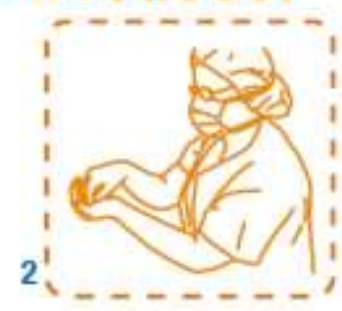

Mergulhe as pontas dos dedos da măo direita no produto, friccionando-as para descontaminat embaixo das unhas $(5$ segundos).
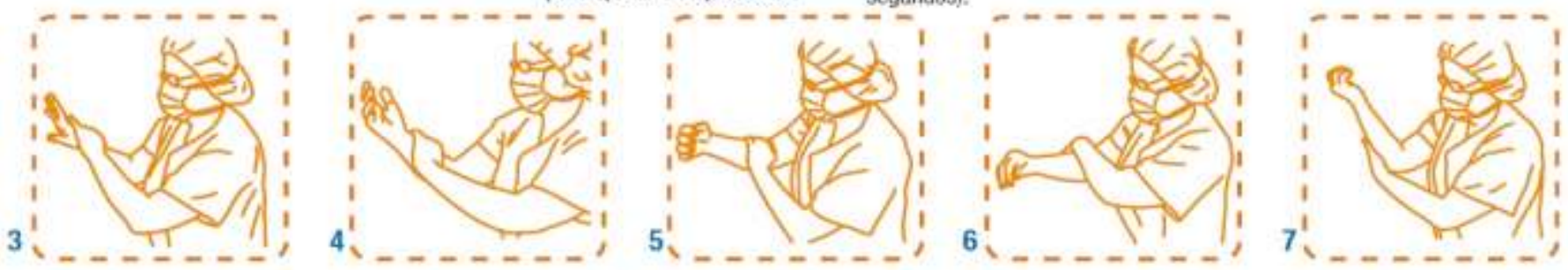

Imagens 3-7. Espalhe o produto no antebraço direito até o cotovelo. Assegure-se de que todas as superficies sejam cobertas pelo produto. Utilize movimentos circulares no antebraço até que o produto evapore completamente (10-15 segundos).
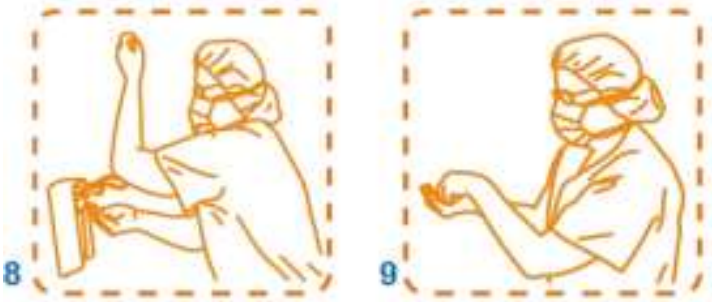

Imagens 8-10: Agora, repita os passos 1 a 7 para a măo e antebraço esquerdo

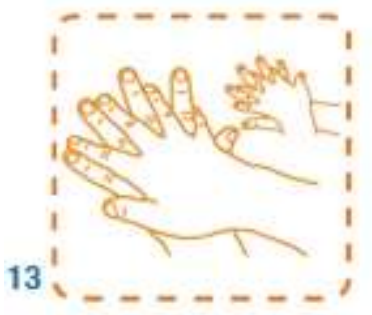

Friccione o produto no dorso da mầ esquerda, incluindo 0 punho, movimentando a palma da mâo direita no dorso esquerdo com movimentos de vai $e$ vern e vice-versa.

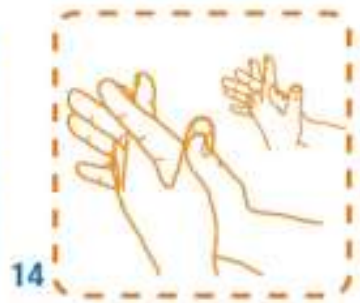

Friccione uma palma contra a outra com 05 dedos entrelaçados.

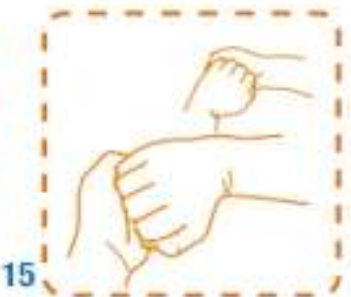

Friccione o dorso dos dedos mantendo-os dentro da palma da outra mâo, em movimentos de vai e vem.

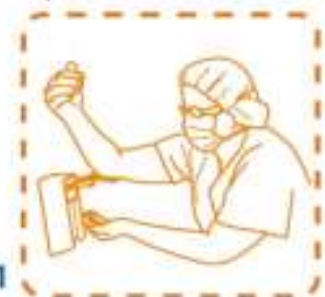

Coloque aproximadamente $5 \mathrm{ml}$ (3 doses) do PBA na palma da măo esquerda como ilustrado, e esfregue ambas as māos ao mesmo tempo até o punho, seguindo todos passos nas imagens 12 a 17 (20-30 segundos).

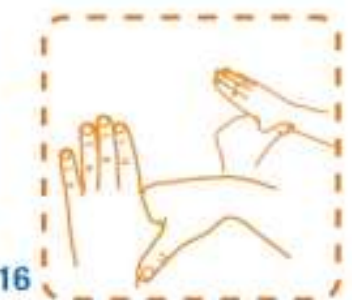

Friccione o polegar da mão esquerda com movimentos de rotação da palma da māo direita enlaçada e vice-versa.

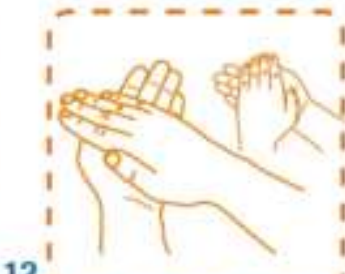

12

Cubra com PBA todas as superficies das mâos até o punho, friccionando palma contra palma, em movimentos rotativos.

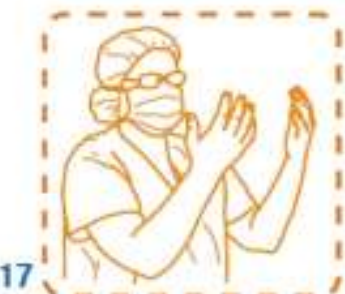

Quando as mâos estiverem secas, 0 avental cinurgica' capote poderá ser vestido e as luvas cinurgicas estereis poderâo ser calcadas.

Fonte: Brasil (2017). 
A Figura 2 apresenta a técnica de antissepsia cirúrgica das mãos com solução alcoólica, onde além dos passos citados para a sua correta realização, traz a informação do tempo necessário de ação do produto para que seja garantido sua eficácia e não traga prejuízos quanto à sua utilização.

Shen et al. (2015), compararam a utilização do método citado por eles como convencional, que é a antissepsia cirúrgica com utilização de escova com clorexidina e PVPI, com a fricção com solução antisséptica alcoólica e trazem que após a realização deste procedimento e após a realização da cirurgia, houve maior redução das culturas positivas coletadas das mãos dos profissionais após a realização do procedimento com o antisséptico alcoólico quando comparado com a escovação utilizando o antisséptico degermante.

Esta pesquisa também menciona a possibilidade de lesão no profissional causada pela escova, além de reações alérgicas ao PVPI e à clorexidina, aumentando o risco de colonização subsequente, e sugerindo ser o antisséptico alcoólico uma forma alternativa com melhores resultados no tempo de aplicação e financeiros, com o fim do uso de escovas.

Outros autores, como Gonçalves, Graziano e Kawagoe (2012), Menezes et al. (2017) e Henning (2017) também afirmam que a técnica com solução alcoólica é mais eficaz do que a clorexidina e reforçam a importância de seguir a técnica recomendada para garantir a sua ação e sua eficácia.

Menezes et al. (2017) realizaram uma pesquisa com 33 profissionais de enfermagem que desenvolveram a antissepsia cirúrgica das mãos através de escovação com clorexidina e solução alcoólica para fricção na pele e apresenta como resultado uma maior eficácia do uso da solução alcoólica quando comparada ao uso da clorexidina.

Maciel (2013) foi além aos demais e traz que quando comparado o uso dos três antissépticos citados neste trabalho, as soluções alcoólicas apresentam desempenho superior na redução de microrganismos após a realização da antissepsia cirúrgica das mãos e possui efeito residual prolongado quando comparado aos demais.

Todas as pesquisas que compararam o uso de solução alcoólica com algum outro método citam ainda o tempo dispensado para realizar a antissepsia cirúrgica das mãos como um fator contribuinte ao seu uso, e por apresentar menor tempo de aplicação quando comparado aos demais métodos.

\section{Considerações Finais}

A utilização dos antissépticos na antissepsia cirúrgica das mãos realizada no pré-operatório é uma ação indispensável para a segurança do paciente cirúrgico. É necessário que o enfermeiro e toda a equipe cirúrgica conheçam os métodos e sua utilização, pois caso venha a ter problemas como falta de padronização ou questões de infra-estrutura, tenham argumentos seguros e técnicos para buscar a melhor forma de sua utilização e forneça embasamento para o enfermeiro, que como agente protagonista de ações em educação em saúde, principalmente relacionados às infecções hospitalares, pode agir de forma técnica como gestor em sua tomada de decisão dentro do centro cirúrgico.

Os estudos encontrados para subsidiar este trabalho mostraram que quando comparada a utilização da clorexidina com o PVPI, a primeira se mostra superior quanto à redução de microrganismos presentes na pele do profissional tanto após a sua utilização quanto em momento posterior, oferecendo melhor ação residual.

Quando comparadas as formas de utilização da clorexidina degermante, os estudos reforçam que tanto por meio de escovação quanto por meio de fricção na pele, ele traz um resultado eficaz, onde afirmam também, que o uso da escova pode ser abandonado frente a alguns fatores, como o risco de lesão na pele do profissional com consequente risco de contaminação deste e do paciente, o tempo de aplicação da técnica, desconforto causado pela técnica e pelo custo gerado à instituição com algo que pode ser substituído sem prejuízo algum quanto à finalidade do procedimento.

Quanto à utilização das soluções alcoólicas, os estudos afirmam que é a melhor opção de antisséptico a ser utilizado na antissepsia cirúrgica das mãos. Trazem que ele possui rápida e ampla ação contra microrganismos presentes nas mãos dos 
profissionais, diminui o tempo da técnica, aumenta a aceitação por parte dos profissionais por não causar desconforto com o uso de escovas, além de diminuir custos com compra de escova/esponja estéril de uso único e descartável.

Com o término desta pesquisa e analisando os estudos citados, conclui-se que nenhum estudo impõe certa substância como absoluta para se realizar a antissepsia cirúrgica das mãos no pré-operatório, porém o método que se mostrou mais eficaz, e, portanto, proporciona uma assistência de enfermagem mais segura ao paciente cirúrgico, foi com o uso de soluções antissépticas alcoólicas.

\section{Referências}

Barreto, R. A. S. S., Rocha-Vilefort, L. O., Souza. A. C. S., Barbosa, M. A., Paula, G. R. \& Palos, M. A. P. (2012). A antissepsia cirúrgica das mãos no cotidiano de um centro cirúrgico. Saúde Santa Maria. 38(2), 9-16. https://doi.org/10.5902/223658344163.

Brasil. Agência Nacional de Vigilância Sanitária. Cartaz de antissepsia ou preparo pré-operatório das mãos. 2014.

Brasil. Agência Nacional de Vigilância Sanitária. Segurança do Paciente em Serviços de Saúde: Higienização das Mãos/Agência Nacional de Vigilância Sanitária. Brasília: Anvisa. 105p.

Brasil. Agência Nacional de Vigilância Sanitária. Técnica para antissepsia cirúrgica das mãos com produto à base de álcool. 2017.

Cunha, E. R. D., Matos, F. G. D. O. A., Silva, A. M. D., Araújo, E. A. C. D., Ferreira, K. A. S. L. \& Graziano, K. U. (2011). Eficácia de três métodos de degermação das mãos utilizando gluconato de clorexidina degermante (GCH 2\%). Revista da Escola de Enfermagem da USP. 45(6), 1440-1445. https://doi.org/10.1590/S0080-62342011000600023.

Darouiche, R. O., Wall Jr, M. J., Itani, K. M., Otterson, M. F., Webb, A. L., Carrick, M. M., Miller. H. J., Awad, S. S., Crosby, C. T., Mosier. M. C. \& Berger, D. H. (2010). Chlorhexidine-Alcohol versus Povidone-Iodine for Surgical-Site Antisepsis. New England Journal of Medicine. 362(1), 18-26. 10.1056/NEJMoa0810988.

Dos Santos, M. R., Burci, L. M. \& Weigert, S. P. (2018). Fatores de Risco e Prevenção de Infecção do Sítio Cirúrgico. Revista Gestão \& Saúde. 18(1), 39-45. ISSN 1984-8153.

Dotto, P. P., Zucuni, C. P., Antes, G. B., Fernandes, M., Favarin, A. G., Christ, R., Santos, B. Z. \& Barboza. V, D, S. (2015). Eficácia de dois métodos de degermação das mãos. Revista de Cirurgia e Traumatologia Buco-maxilo-facial. Camaragibe. 15(3), 07-14.

Duarte, I. G. L., \& Leite, M. D. (2013). Paramentação cirúrgica: artigo de revisão. Revista Médica de Minas Gerais. 23(3), 343-346. 10.5935/22383182.20130054 .

GIL, C. A. (2017). Como Elaborar Projetos de Pesquisa, (6a ed.), Atlas.

Gök, F., Kabu, F., Özbayir, T. (2016). Surgical hand washing: A systematic review. Int J Antisep Disinfect Steril. 1(1), 23-32. 10.14744/ijads.2016.32042.

Gonçalves, K. J., Graziano, K. U., Kawagoe, J. Y. (2012). Revisão sistemática sobre antissepsia cirúrgica das mãos com preparação alcoólica em comparação aos produtos tradicionais. Revista da Escola de Enfermagem da USP. 46(6), 1484-1493.

Goulart, D. R., Assis, E. A., Souza, M. T. (2011). Avaliação microbiológica da antissepsia pré-operatória das mãos. Rev. cir. traumatol. buco-maxilofac. Camaragibe. 11(3), 103-112. ISSN 1808-5210.

Hennig, T. J., Werner, S., Naujox, K., \& Arndt, A. (2017). Chlorhexidine is not na essential component in alcohol-based surgical hand preparation: a comparative study of two hand rubs based on a modified EN 12791 test protocol. Antimicrobial Resistance \& Infection Control.6(1), 1-6. https://doi.org/10.1186/s13756-017-0258-0.

Jarral, O. A., McCormack, D. J., Ibrahim, S. \& Shipolini, A. R. (2011). Should surgeons scrub with chlorhexidine or iodine prior to surgery? Interactive cardiovascular and thoracic surgery. 12(6), 1017-1021. 10.1510/icvts.2010.259796.

Lopes, A. E. R. (2019). Comparação da tolerância e aceitabilidade de cirurgiões à aplicação de solução alcoólica versus aplicação de antissépticos degermantes para o preparo cirúrgico das mãos: um ensaio clínico pareado. Doctoral Thesis. Escola de Enfermagem de Ribeirão Preto. Universidade de São Paulo. http://10.11606/T.22.2020.tde-19112019-192529.

Maciel, M. A. (2013). Lavagem pré-cirúrgica das mãos: uma revisão de literatura. Trabalho de Conclusão de Curso. Universidade Federal da Bahia (UFBA).

Menezes, R. M., Cardoso, V., Hoehr, C. F., Bulle, D., Burgos, M. S., Benitez, L. B. \& Renner, J. D. P. (2016). Avaliação microbiológica da antissepsia préoperatória das mãos de profissionais de enfermagem de um centro cirúrgico. Revista de Epidemiologia e Controle de Infecção. Santa Cruz do Sul. 1(1), 178191. ISSN 2238-3360. https://doi.org/10.17058/reci.v1i1.8288.

Nunes, M. B. de S. (2016). A atuação do enfermeiro no controle de infecção de sítio cirúrgico nos cuidados pré e pós-operatórios. Universidade Federal Fluminense. $92 \mathrm{f}$.

Prates, J., Monteiro, A. B., Lopes, F., Stumpfs, D., Guglielmi, G., Narvaez, G., Bobsin, R. C. \& Caregnato, R. C. A. (2016). Implantação de antissepsia cirúrgica alcoólica das mãos: Relato de Experiência. Revista SOBECC. 21(2), 116-121. 10.5327/Z1414-4425201600020009. 
Research, Society and Development, v. 10, n. 9, e15710917836, 2021

(CC BY 4.0) | ISSN 2525-3409 | DOI: http://dx.doi.org/10.33448/rsd-v10i9.17836

Primo, M. G. B., Ribeiro, L. C. M., Figueiredo, L. F. D. S., Sirico, S. C. A. \& Souza, M. A. D. (2010). Adesão à prática de higienização das mãos por profissionais de saúde de um Hospital Universitário. Revista Eletrônica de Enfermagem. 12(2), 266-271. 10.5216/ree.v12i2.7656.

Rehman, H., Nizami, A. Y. M. S. M. \& Shafi, A. (2010). Surgical hand antisepsis: What surgeons need to know. Nishtar Medical Journal. 2 , 14-22.

Shen, N. J., Pan, S. C., Sheng, W. H., Tien, K. L., Chen, M. L., Chang, S. C., \& Chen, Y. C. (2015). Comparative antimicrobial efficacy of alcohol-based handrub and conventional surgical scrub in a medical center. Journal of Microbiology, Immunology and Infection. 48(3), 322-328. https://doi.org/10.1016/j.jmii.2013.08.005.

Silva, E. L. D., \& Menezes, E. M. (2005). Metodologia da pesquisa e elaboração de dissertação. (4a ed.), UFSC. 